\title{
Understanding the Role of the Constituting Elements of the AlCoCrFeNi High Entropy Alloy through the Investigation of Quaternary Alloys
}

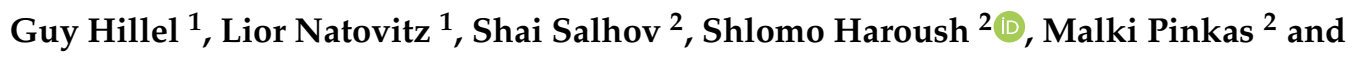 \\ Louisa Meshi ${ }^{1, *(D)}$ \\ 1 Department of Materials Engineering, Ben-Gurion University of the Negev, P.O.B 653, \\ Beer-Sheva 8410501, Israel; guyhill@post.bgu.ac.il (G.H.); natovitz@post.bgu.ac.il (L.N.) \\ 2 Nuclear Research Center Negev, P.O.B. 9001, Beer-Sheva 841900, Israel; shainbars@gmail.com (S.S.); \\ monih6655@gmail.com (S.H.); malkip@gmail.com (M.P.) \\ * Correspondence: Louisa@bgu.ac.il; Tel.: +972-54-5909283
}

Received: 2 September 2020; Accepted: 22 September 2020; Published: 23 September 2020

\begin{abstract}
Quinary AlCoCrFeNi high entropy alloy (HEA) is one of the most studied alloys in the recent decade due to its outstanding properties. However, it is still far from becoming an applicable industrial alloy. To our understanding, in order to promote this, the role of elements, constituting the quinary alloy, needs to be defined. Knowing the role of each element, modification of the quinary alloy toward minimization of its disadvantages will be possible. In the current research, we shed some light on this subject, presenting a thorough investigation of the microstructure (carried out using scanning and transmission electron microscopy) and mechanical properties, performed by microhardness and fractography post small punch test (SPT), of five equiatomic quaternary alloys, constituting the quinary system, namely: $\mathrm{CoCrFeNi}$, $\mathrm{AlCoFeNi}$, $\mathrm{AlCoCrNi}$, $\mathrm{AlCoCrFe}$, and $\mathrm{AlCrFeNi}$. CoCrFeNi (i.e., w/o Al) was found to be Face Centered Cubic (FCC) solid solution, exhibiting relatively low micro-hardness and ductile fracture post SPT measurement. AlCoFeNi (i.e., w/o Cr) was essentially single phase B2. Other alloys had a mixed BCC + B2 dual phase content with variable microstructures and sizes of particles. The fine microstructure of the alloy without Ni implies eutectic solidification or spinodal decomposition. This fine microstructure imposed remarkable high hardness though the alloy was too brittle and unmachinable. Among the BCC/B2 mixture alloys, Fe and Co-less ones resembled the most quinary $\mathrm{AlCoCrFeNi}$ in terms of microstructure and mechanical properties.
\end{abstract}

Keywords: high entropy alloys; microstructure; hardness; small punch test (SPT); structural defects; metallurgy

\section{Introduction}

In contrast to classical metallurgy, where alloys contain one major constituent and minor alloying elements-High Entropy Alloys (HEAs)-present new concept of alloy's design. These alloys compose of at least five elements with equal/near-equal atomic ratio (5 to 35 at.\%) [1]. The AlCoCrFeNi alloy became one of the most studied alloys in the HEA field, starting from [2]. This alloy exhibited a good combination of yield strength (1379 MPa) and ductility (22.7\%) [3], and high softening resistance [4]. It is known that this equiatomic alloy tends to solidify in a dendritic regime. In [5], it was reported that both interdendrite (ID) and dendrite (DR) regions of this quinary alloy consist of Fe-Cr rich body centered cubic (BCC) particles embedded in the Al-Ni rich ordered BCC (B2) matrix. Furthermore, this alloy's microstructure can be changed by altering the solidification parameters (heating temperature, holding time, etc.) [6]. Alongside its many advantages, this alloy has disadvantages such as the formation 
of the $\sigma$ phase, which embrittles the alloy at high temperatures [7]. In order to promote the use of the AlCoCrFeNi-based alloys in the industry and perform rational design of new high entropy alloys, the role of each element in the original AlCoCrFeNi quinary alloy must be defined. This can be performed through detailed investigation of alloys composed of quaternary combinations of the $\mathrm{Al}-\mathrm{Co}-\mathrm{Cr}-\mathrm{Fe}-\mathrm{Ni}$ elements. It should be noted that these quaternary alloys are not necessarily high entropy themselves. CoCrFeNi alloy [8,9], for example, was characterized as single face centered cubic (FCC) solid solution. Therefore, it can be presumed that $\mathrm{Al}$ stabilizes the BCC solid solution phase in the quinary alloy. This assumption was checked in [4], where the $\mathrm{Al}_{x} \mathrm{CoCrFeNi}$ system was studied. It was found that an increase in the Al content indeed stabilizes the BCC structure. The role of the other four elements in the quinary alloy is still under question. For example, although $\mathrm{AlCrFeNi}[8,10]$, $\mathrm{AlCoFeNi}$, and [11,12] AlCoCrNi [13] alloys were studied, role of $\mathrm{Co}, \mathrm{Cr}$, and $\mathrm{Fe}$ in the quinary alloy was not determined. It should be noted that in [11], it was stated that without $\mathrm{Cr}$, a single phase B2 forms. Current research was undertaken to understand the role of the elements constituting the AlCoCrFeNi HEA.

In an attempt to isolate the effect of each element on the microstructure and composition of the different phases in quinary $\mathrm{AlCoCrFeNi}$ alloy, five quaternary alloys were cast systematically with an equiatomic composition, removing one element at a time. To make it clearer, each alloy was designated in the manuscript by its composition and the element that is lacking (compared to the quinary composition) is written in parenthesis. For example, $\mathrm{AlCoCrNi}(w / o ~ F e)$ is a quaternary alloy without $\mathrm{Fe}$, compared to the quinary AlCoCrFeNi.

\section{Materials and Methods}

Quaternary ingots with nominal equal atomic composition of $\mathrm{AlCoCrNi}(w / o \mathrm{Fe}), \mathrm{AlCoFeNi}$

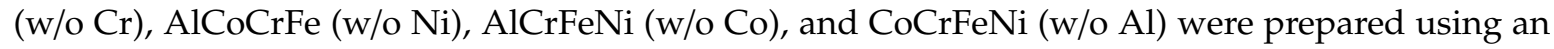
arc melting method. The purity of the raw elements was above $99.9 \%$. The materials were melted in a water-cooled copper mold under an ultra-high purity (UHP) argon atmosphere. The ingots were re-melted five times in order to ensure chemical homogeneity. For $x$-ray diffraction (XRD), the specimens were cut and polished on $15 \mu \mathrm{m} \mathrm{SiC} \mathrm{lapping} \mathrm{disks.} \mathrm{Data} \mathrm{were} \mathrm{collected} \mathrm{on} \mathrm{a} \mathrm{D/MAX-2000} \mathrm{diffractometer}$ (Rigaku global corporation, Austin, TX, USA) equipped with a graphite monochromator for $\mathrm{Cu} \mathrm{K} \alpha$ radiation $(\lambda=0.154056 \mathrm{~nm})$.

Scanning electron microscopy (SEM) analysis was carried out on a FEI-VERIOS XHR 460L (ThermoFisher Scientific, Hillsboro, OR, USA). For SEM analysis, specimens were mounted in bakelite, mechanically ground on 4000 grit $\mathrm{SiC}$ papers, polished on $3 \mu \mathrm{m}$ and $1 \mu \mathrm{m}$ diamond paste, and $0.04 \mu \mathrm{m}$ colloidal $\mathrm{SiO}_{2}$ suspension.

Transmission Electron Microscopy (TEM) analysis was performed on JEOL JEM-2100F operating at $200 \mathrm{kV}$ equipped with JEOL JED-2300T Energy Dispersive x-ray Spectrometer (EDS) (JEOL LTD, Tokyo, Japan). For this purpose, discs of $3 \mathrm{~mm}$ in diameter were mechanically ground on $5 \mu \mathrm{m} \mathrm{SiC}$ paper down to a thickness of approximately $100 \mu \mathrm{m}$, polished on a Gatan dimple grinder, and ion milled using a Gatan Precision Ion Polishing System-PIPS2 (Gatan inc. Ametek, Pleasanton, CA, USA) with 3-5 keV Ar ions to achieve electron transparency.

Small punch test (SPT) samples were cut into $8 \mathrm{~mm} \times 8 \mathrm{~mm} \times \sim 0.5 \mathrm{~mm}(0.500 \pm 0.015 \mathrm{~mm})$ thick samples and polished on 1200 grit SiC paper. The ball diameter was $2.48 \mathrm{~mm}$. The SPT was conducted in following way: (1) clamping of the specimen between the dies under $2500 \mathrm{~N}$; (2) pre loading up to $15 \mathrm{~N}$ and balancing the stoke transducer (Instron COD); and (3) pushing the ball into the specimen under stroke control at a speed of $0.2 \mathrm{~mm} / \mathrm{min}$ up to failure. The end test criterion was maximal load. Specimen failure fracture mode was characterized by SEM.

Vickers microhardness measurements were performed on a Micromet microhardness tester (Buehler, Lake Bluff, IL, USA). Measurements were made on polished samples using a $100 \mathrm{gr}$ load applied for $10 \mathrm{~s}$. Indent size was smaller than the dimensions of the studied area. Measurements were conducted 10 times on each specimen. Since the morphology of the dendrite and interdendrite areas 
was noticeably different, there was no problem in discerning the two areas while performing the microhardness tests.

\section{Results and Discussion}

At first, qualitative assessment of the phase content of studied quaternary alloys was performed by XRD. Figure 1 shows the XRD patterns taken from the studied alloys. Due to the almost identical lattice parameters of the BCC and B2 phases, it is impossible to differentiate between the BCC/B2 mixture and single B2 phase using only laboratory bulk x-ray diffraction, since the diffraction peaks corresponding to (110), (200), and (211) planes overlap and in the bulk specimens, strong preferred orientation exists. Thus, when (100) and (210) peaks of the primitive B2 appeared, the alloys' phase content was regarded as a duplex structure of disordered BCC and B2, namely a BCC + B2 mixture, which was specified by TEM analysis. Consequently, it was concluded that all samples containing $\mathrm{Al}$ consisted of a disordered BCC and an ordered B2 phase mixture, similar to the quinary AlCoCrFeNi alloy, as reported in [5]. For the AlCoFeNi (w/o Cr) alloy, the peaks that can be referred to both BCC and B2 phases were found to be broader, compared to those corresponding to B2 only (such as (210)), as seen in Figure 1b. This observation implied on microstrains and/or small grain size of the BCC phase's particles with respect to the B2.
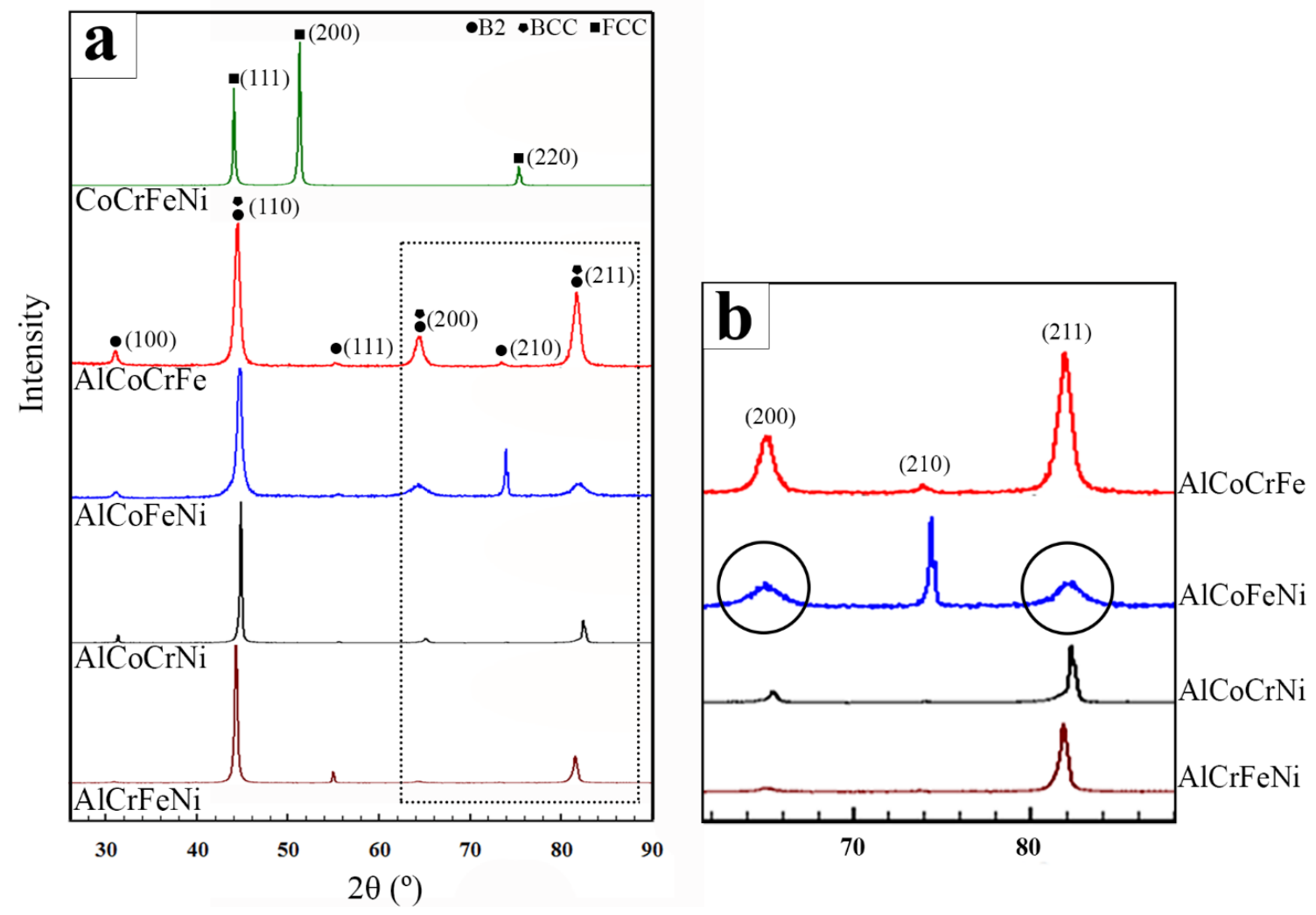

Figure 1. (a) X-ray diffractograms (XRD patterns) of the studied quaternary alloys. (b) Magnified image of a dotted rectangle marked on (a). It can be seen that the (210) peak of the B2 phase is much narrower in the AlCoFeNi (w/o Cr) alloys' diffractogram, than overlapping (200) and (211) B2/BCC peaks (circled).

CoCrFeNi (w/o Al) alloy is an exception among the studied alloys. Its XRD pattern (Figure 1a) revealed that this alloy is a single-phase FCC solid-solution, which is in agreement with [14]. SEM and TEM analysis confirmed this conclusion (see Figure 2). CoCrFeNi (w/o Al) alloy consisted of grains exceeding $0.2 \times 1.4 \mathrm{~mm}$ in size (see inset in Figure $2 \mathrm{a}$ ), containing relatively high dislocation density (see Figure $2 b$ ). It should be noted that no ordered domains with the $\mathrm{L}_{2}$ structure were detected. 
Electron diffraction taken with a large selected area aperture, indexed in terms of the FCC structure with a $\sim 3.6 \AA$, is shown in the inset of Figure $2 b$. Thus, it can be inferred that Al stabilizes BCC/B2 formation, as was proposed in [14].
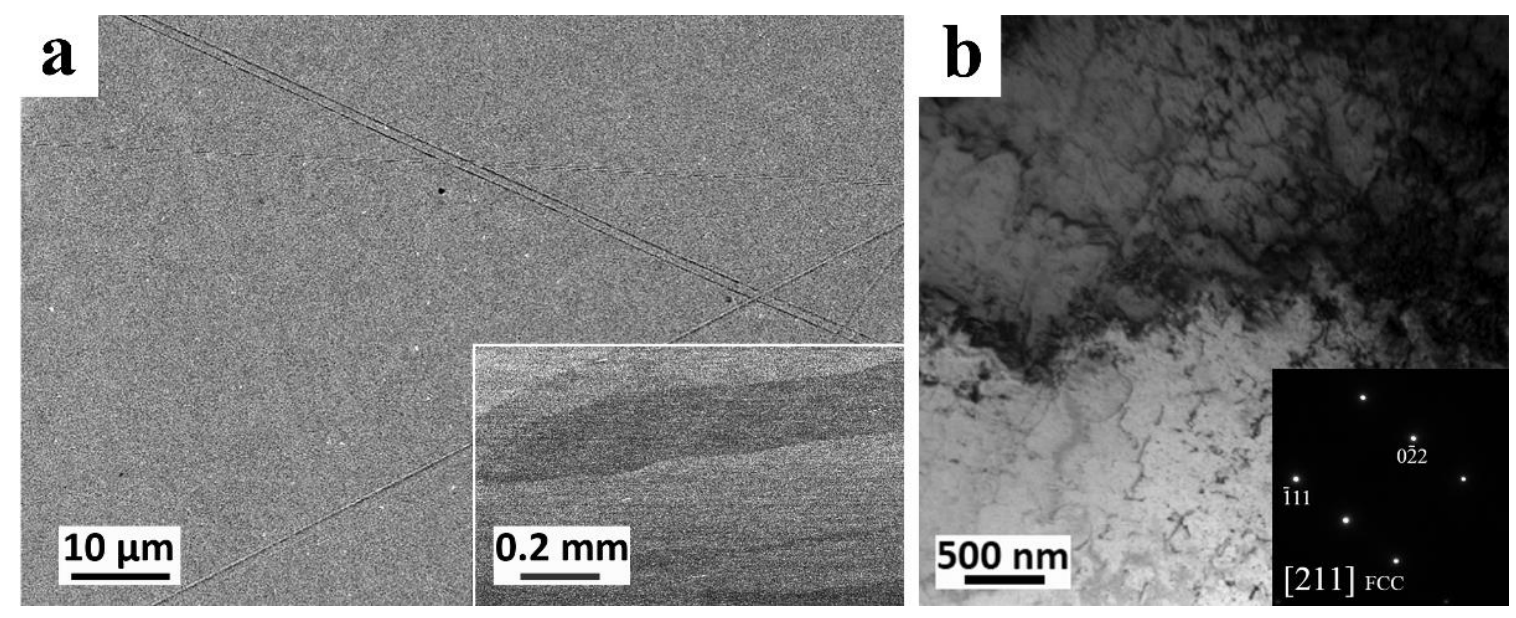

Figure 2. Microstructure of the CoCrFeNi (w/o Al) alloy. (a) SEM general view image. Low magnification image is shown in the inset. (b) Typical bright field (BF) TEM image showing high dislocation density. Selected area electron diffraction (SAED) pattern taken from a grain of the CoCrFeNi (w/o Al) alloy at [211] orientation is shown in the inset.

Initial microstructural evaluation of the $\mathrm{BCC}+\mathrm{B} 2$ dual-phase alloys was performed using SEM (Figure 3). Figure 3a,d exhibit dendritic solidification of the AlCrFeNi (w/o Co) and AlCoCrNi (w/o Fe) alloys, respectively, which is similar to the quinary AlCoCrFeNi alloy [5]. These two quaternary alloys presented different morphologies in the ID and DR regions: coarser and finer, respectively. Morphology of these different areas are shown in Figure 3b,c for the AlCrFeNi (w/o Co) alloy, and Figure 3e,f for the $\mathrm{AlCoCrNi}$ (w/o Fe) alloy. These differences also resemble the quinary $\mathrm{AlCoCrFeNi}$ alloy. Among these two alloys, pronounced compositional DR/ID differences were obtained only for the AlCoCrNi (w/o Fe) alloy, see Table 1. The difference was mainly manifested by the variation of the Cr content. The coarse microstructure of the ID area contained high $\mathrm{Cr}$ content, with a B2/BCC phase ratio of approximately 44/56, while in the DR region, the Cr content was almost three times less with the B2/BCC phase ratio of approximately 85/15 (the measurements were performed on SEM images using ImageJ software [15]). This result implies that $\mathrm{Cr}$ promotes BCC formation on the expense of the B2. Investigation of the $\mathrm{AlCoFeNi}(\mathrm{w} / \mathrm{o} \mathrm{Cr}$ ) alloy confirmed this conclusion. In Figure $3 \mathrm{~g}$, the morphology of the AlCoFeNi (w/o Cr) appears uniform, possessing $150 \mu \mathrm{m}$ equiaxed grains. Detailed TEM analysis of this alloy confirmed that it mostly consists of the B2 phase with nanosized BCC inclusions (see Figure 4). This result is in-line with [11]. Moreover, the small size of the BCC inclusions explains the broadening of the overlapping B2/BCC peaks in the x-ray diffractogram (see Figure 1b). Thus, it can be concluded that $\mathrm{Cr}$ stabilizes the BCC structure (i.e., reduces ordering phenomenon).

Table 1. Average area composition (in at.\%) of dendrite (DR) and interdendrite (ID) regions of the $\mathrm{AlCoCrNi}$ (w/o Fe) alloy, as analyzed by energy dispersive spectrometry (EDS) in scanning electron microscope (SEM). Standard deviation of the measurements was significantly smaller than expected standard-less EDS accuracy.

\begin{tabular}{ccccccc}
\hline Alloy & Region & Al & Co & Cr & Fe & Ni \\
\hline \multirow{2}{*}{ AlCoCrNi } & DR & 20.4 & 34.8 & 16.8 & - & 28.1 \\
& ID & 11.5 & 28.1 & 42.2 & - & 18.2 \\
\hline
\end{tabular}



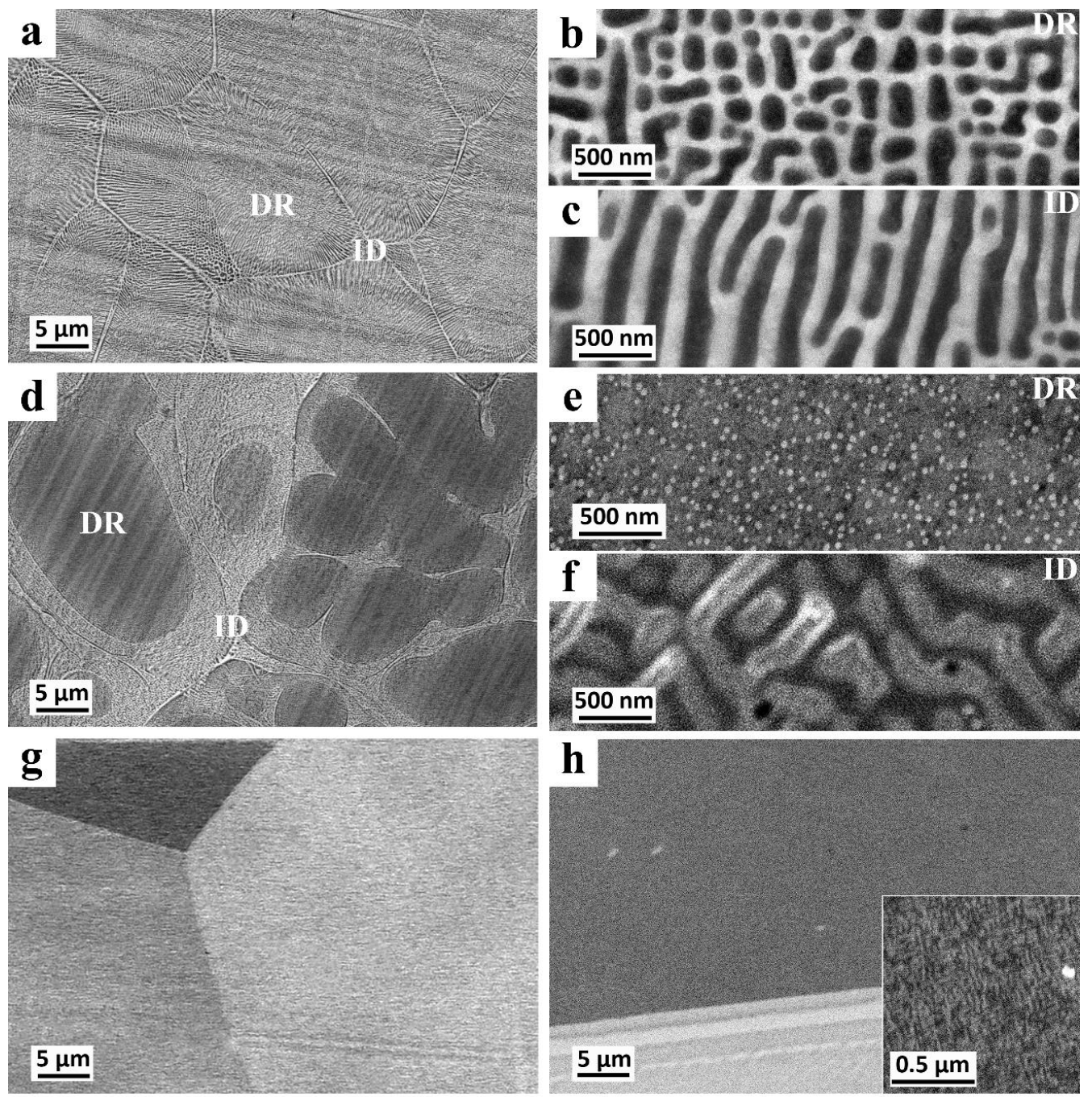

Figure 3. Scanning Electron Microscope (SEM) investigation of the quaternary alloys. (a) Back scattered (BS) SEM general view image of the AlCrFeNi (w/o Co) alloy. DR and ID areas are shown in (b,c) images, respectively. (d) (BS) SEM general view image of the AlCoCrNi (w/o Fe) alloy. DR and ID areas are shown in (e,f) images, respectively. (g,h) (BS) SEM general view images of the AlCoFeNi $(\mathrm{w} / \mathrm{o} \mathrm{Cr}$ ) and $\mathrm{AlCoCrFe}(\mathrm{w} / \mathrm{o} \mathrm{Ni})$ alloys, respectively. Insert in (h) shows high resolution (using in-lens secondary electron detector) SEM image of the alloy without Ni.

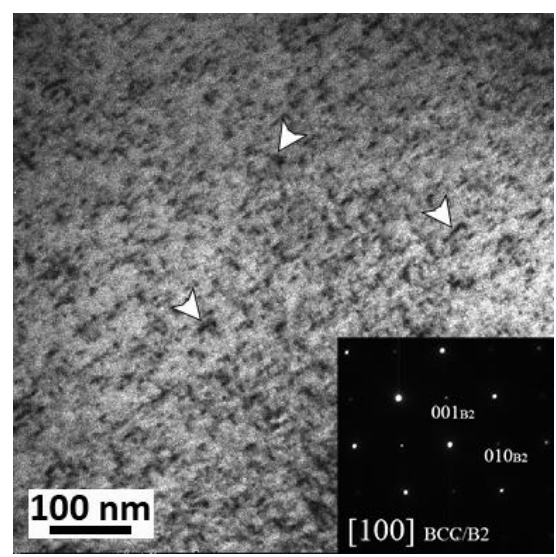

Figure 4. Typical Transmission Electron Microscopy (TEM) image and Selected Area Electron Diffraction (SAED) pattern, taken from the AlCoFeNi (w/o Cr) alloy at [100] orientation. Matrix was found to be B2 and particles (marked by arrows) have a BCC structure. 
$\mathrm{AlCoCrFe}(\mathrm{w} / \mathrm{o} \mathrm{Ni})$ alloy exhibited a fine uniform microstructure, which might be a result of spinodal decomposition or eutectic solidification (see Figure $3 \mathrm{~h}$ and insert therein). This alloy was very brittle (essentially unmachinable) and exhibited exceptional hardness (will be discussed later in this manuscript). The TEM study of the $\mathrm{AlCoCrFe} \mathrm{(w/o} \mathrm{Ni)} \mathrm{alloy} \mathrm{allowed} \mathrm{concluding} \mathrm{that} \mathrm{the} \mathrm{fine}$ microstructure is a mixture of BCC and B2 phases (see Figure $5 a, b$ ).
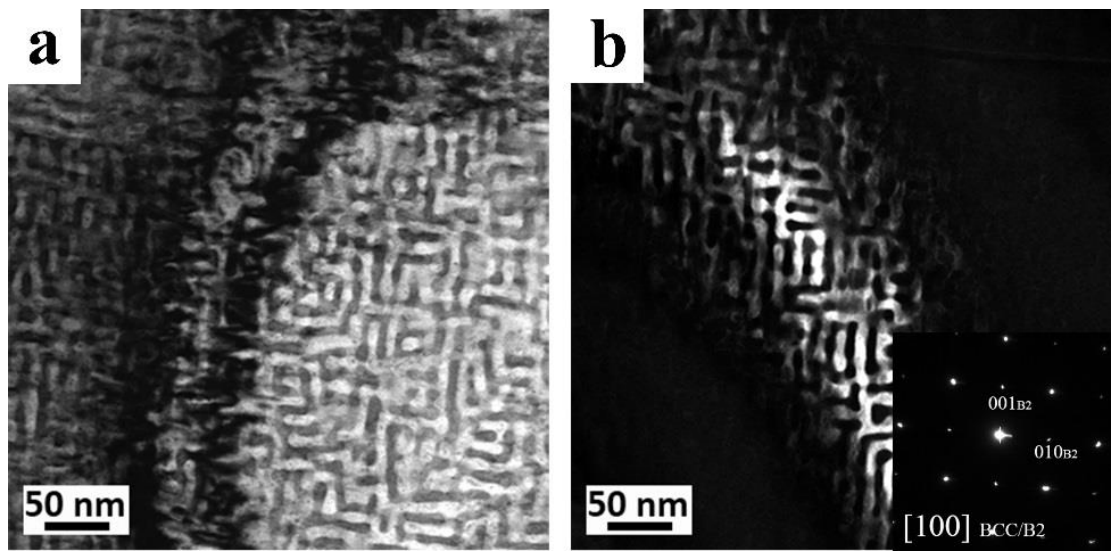

Figure 5. TEM study of the AlCoCrFe (w/o Ni) alloy. (a,b) Bright field (BF) and dark field (DF) (taken in $\left.\mathrm{g}=(010)_{\mathrm{B} 2}\right)$ TEM images. Areas of B2 phase are illuminated in image $(\mathbf{b})$. SAED pattern taken along $[100]_{\mathrm{B} 2 / \mathrm{BCC}}$ orientation is shown in the inset.

As noted earlier, the microstructures of $\mathrm{AlCrFeNi}$ (w/o Co) and $\mathrm{AlCoCrNi}$ (w/o Fe) were similar (see Figures 3a-c and 3d-f, respectively). In both alloys, DR areas consist of small rounded BCC particles embedded in the B2 matrix. ID areas of the two alloys has the same phase content as DR, characterized by more elongated (than the DR particles) morphology and coarser particles (see Figures 6 and 7). The difference between these alloys is manifested mainly by the size of particles: BCC particles in the DR area of the AlCrFeNi (w/o Co) alloy were an order of magnitude larger, $0.142 \pm 0.061 \mu \mathrm{m}^{2}$, than those in the $\mathrm{AlCoCrNi}(\mathrm{w} / \mathrm{o} \mathrm{Fe})$ alloy at $0.022 \pm 0.007 \mu \mathrm{m}^{2}$. In addition, differences were observed in the specific shape of the particles in the ID regions. ID region of the AlCoCrNi (w/o Fe) alloy has a uniform BCC/B2, Chinese-letter like morphology, as shown in Figure 6c,d, which is similar to the quinary AlCoCrFeNi alloy. This area displays a relatively high density of dislocations in both phases. Dislocations are marked by arrows in Figure 6d. The ID area of the AlCrFeNi (w/o Co) alloy was somewhat different, exhibiting an elongated parallel alternating B2/BCC particles, as shown in Figure 7c,d. It is interesting to note that in this alloy, only the BCC phase exhibited a high density of dislocations (see Figure 7a,c respectively), while B2 seemed to be dislocation free. This analysis was performed in 2-beam conditions [16], which allowed us to conclude $a / 2<111>$ Burgers vector for the observed dislocations in the BCC particles. No superdislocations with $<100>$ vector were detected. Since in [5,7], the quinary AlCoCrFeNi alloy was studied using the same TEM sample preparation methods as here and exhibited no dislocations, we believe that the dislocations observed in this case are not a result of the sample preparation method. The dislocations, obtained in these two alloys, probably point to some degree of misorientation between the B2 and BCC lattices, which was not observed in the quinary and other quaternary alloys. Thus, it is plausible to assume that both Fe and Co contribute to a reduction in this mismatch. This observation implies that the presence of dislocations in different phases does not depend only on the crystallographic structure, but also on the composition. Moreover, appearance of dislocation in both B2 and BCC phases in one alloy vs. high dislocation density, only in the BCC phases in the other alloy, implies different hardness values of the two phases, one with respect to the other. If the B2 and BCC phases exhibit similar hardness, dislocations will appear in both phases, as observed in the AlCoCrNi (w/o Fe) alloy (see Figure 6d). Otherwise, dislocations will appear only in the softer phase, which is apparently BCC in the AlCrFeNi (w/o Co) alloy (see Figure 7c). Appearance of the dislocations in the softer phase in complex systems is 
a known strain relief mechanism. As an example, in [7], a high dislocation density in the FCC phase appearing in quinary AlCoCrFeNi HEA was reported. In that article, FCC appeared alongside with $\mathrm{BCC}, \mathrm{B} 2$, and $\sigma$ phases, which did not exhibit dislocations and were considered to be much harder than the FCC phase. Going back to the discussed here quaternary alloys (i.e., w/o Fe and w/o Co), it was noted that in both alloys, the ID area exhibited higher dislocation density relative to the DR area, imposing higher micro-hardness values for the ID region (see Table 2).
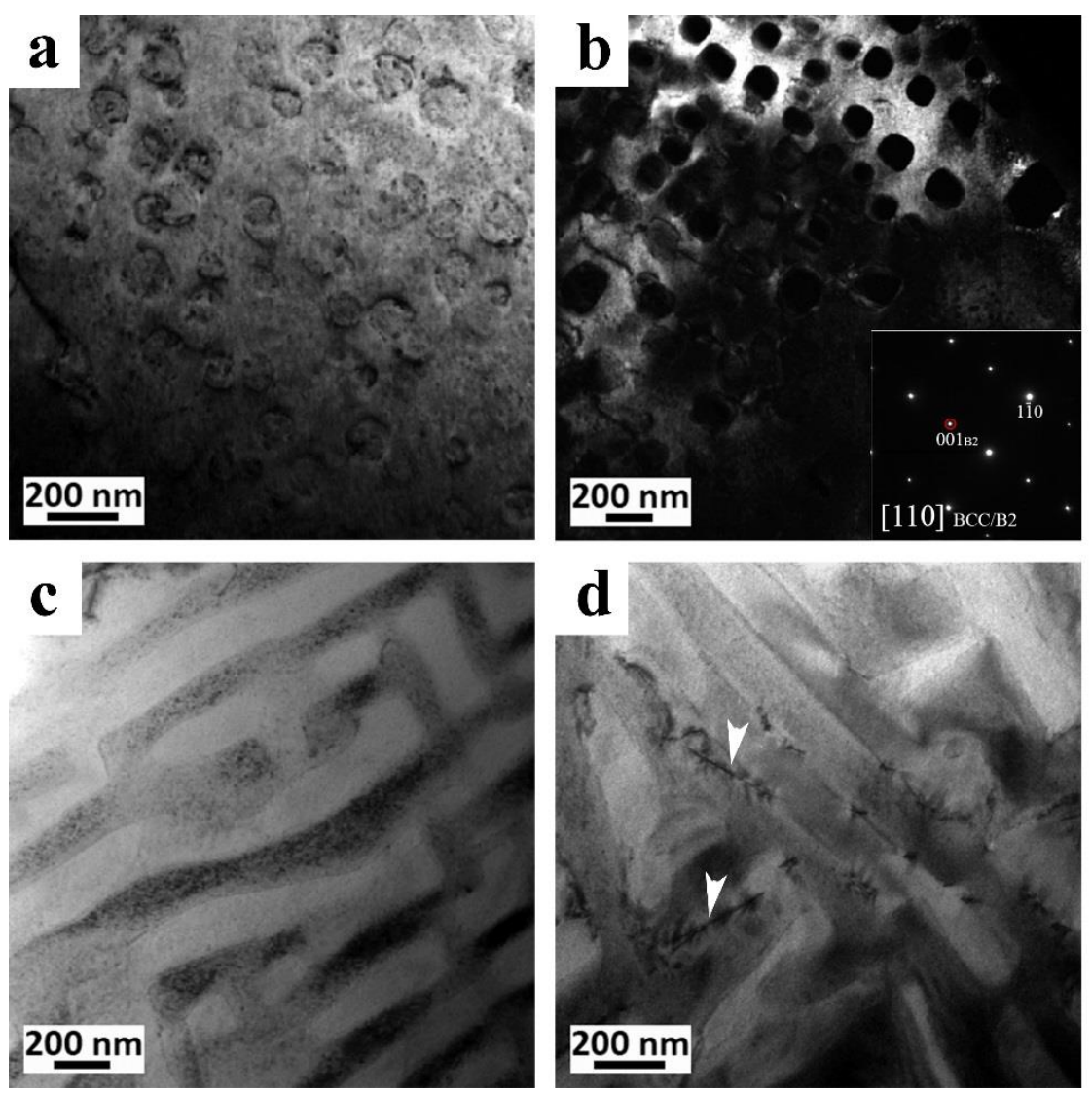

Figure 6. (a) BF and (b) DF (taken in $\left.g=(001)_{\mathrm{B} 2}\right)$ TEM images of the DR area of the AlCoCrNi (w/o Fe) alloy. SAED pattern along [110] orientation is shown in the inset. B2 phase is the matrix here since it lit in the DF image. Microstructure of the ID area of the AlCoCrNi (w/o Fe) alloy is shown in (c,d). Dislocations are marked by arrowheads.

In general, the assessment of the mechanical properties of these alloys is not an easy task since the arc melting process produces a low amount of material. Here, we performed this evaluation using micro-hardness (Table 2) and the small punch test (SPT). The results presented hereafter imply that the mechanical properties of these alloys are governed mainly by their microstructure. The CoCrFeNi (w/o Al) alloy exhibited the lowest hardness values $(132 \mathrm{HV})$, which is in line with its FCC single phase content. The micro-hardness values of other studied here alloys, composed of BCC $+\mathrm{B} 2$ mixture, follows the Hall-Petch relationship (and not inverse Hall-Petch, despite the nano-size of the particles, which is in-line with the related study reported in [17]). For the finest microstructure (AlCoCrFe w/o Ni alloy), the highest microhardness values were obtained. For the coarser microstructure (AlCoFeNi w/o Cr alloy, which was essentially single B2 phase with large B2 grains), the lowest (between the BCC $+\mathrm{B} 2$ dual phase alloys) value was measured. Both the AlCoCrNi (w/o Fe) and AlCrFeNi (w/o Co) alloys exhibited hardness values similar to the quinary alloy in the DR and in the ID areas, which correlates with their similar microstructures. Even in these similar alloys, the AlCoCrNi (w/o Fe) micro-hardness was found to be higher than that of the $\mathrm{AlCrFrNi}$ (w/o Co) alloy, since its microstructure was finer. 

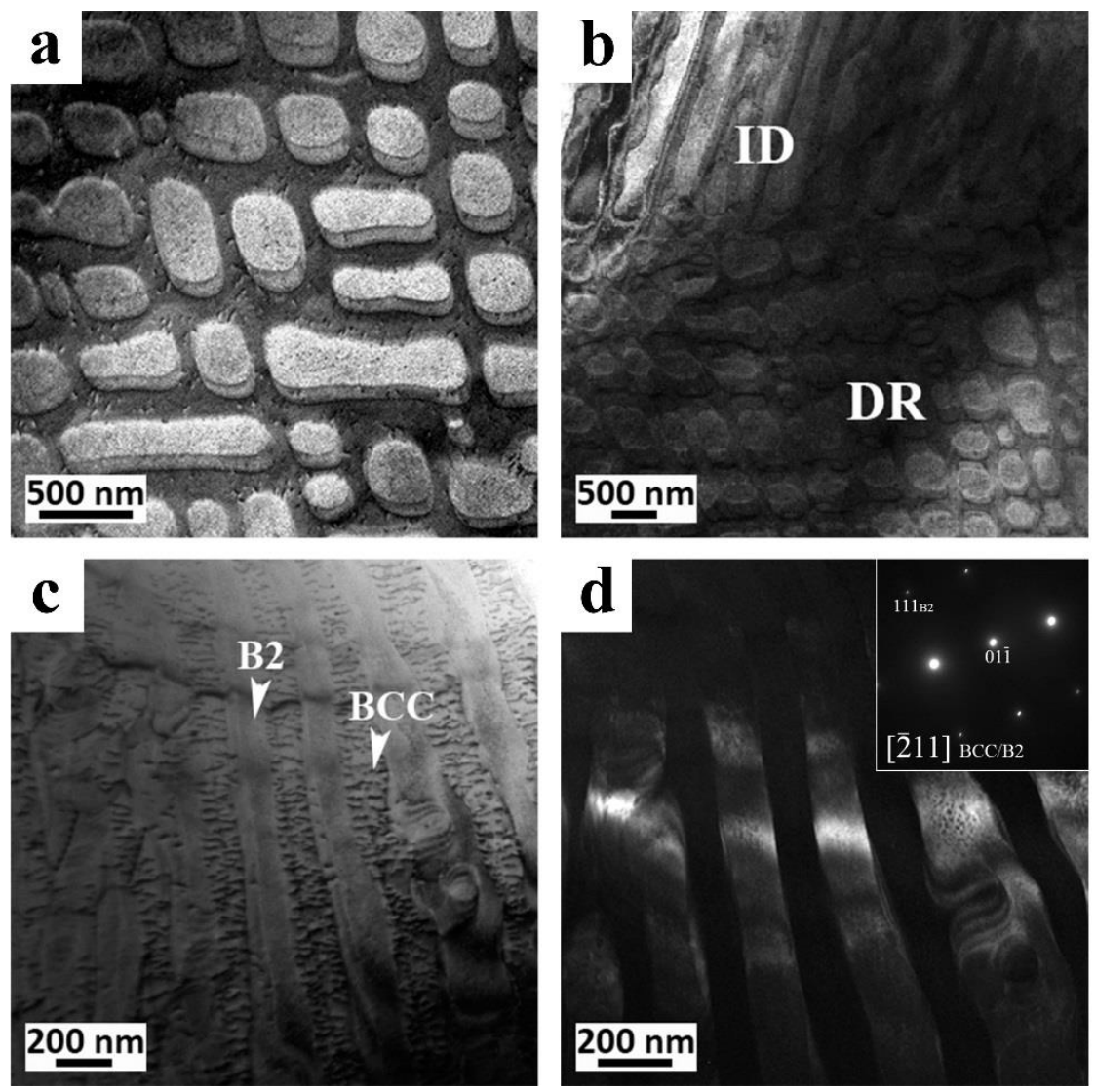

Figure 7. (a) BF TEM images of the DR area of the AlCrFeNi (w/o Co) alloy. (b) Exhibits an interface between the ID and DR areas. (c,d) BF and DF TEM images of the ID area. Corresponding SAED is shown in the inset. It can be seen that the phase with high dislocation density is BCC, since it does not light up on DF image taken with $g=(111)$, shown in $(\mathbf{d})$.

Table 2. A summary of the micro-hardness values (in HV0.1) of the studied alloys and the quinary AlCoCrFeNi alloy. Microhardness value of the latter was taken from [18].

\begin{tabular}{ccc}
\hline Alloy & Region & Hardness \\
\hline \multirow{2}{*}{$\mathrm{AlCrFeNi}(w / o ~ C o)$} & DR & $460 \pm 16$ \\
& ID & $501 \pm 12$ \\
\hline \multirow{2}{*}{$\mathrm{AlCoCrNi}(w / o$ Fe) } & DR & $540 \pm 12$ \\
& ID & $601 \pm 31$ \\
\hline $\mathrm{AlCoFeNi}(w / o ~ C r)$ & - & $446 \pm 8$ \\
\hline $\mathrm{AlCoCrFe}(w / o ~ N i)$ & - & $721 \pm 15$ \\
\hline $\mathrm{CoCrFeNi}(w / o ~ A l)$ & - & $132 \pm 1$ \\
\hline \multirow{2}{*}{$\mathrm{AlCoCrFeNi}[18]$} & $\mathrm{DR}$ & $469 \pm 20$ \\
& ID & $520 \pm 20$ \\
\hline
\end{tabular}

To further assess the mechanical properties, SPT was conducted on all investigated alloys, except for $\mathrm{AlCoCrFe}(\mathrm{w} / \mathrm{o} \mathrm{Ni})$ due to its high brittleness. After SPT, each alloy was subjected to a fractographic evaluation using SEM, in order to characterize the fracture type (see Figure 8a-d). As expected, the FCC CoCrFeNi (w/o Al) alloy fractured in a ductile mode, manifested by dimples, characteristic of micro-void coalescence (see Figure 8d). AlCoCrNi (w/o Fe), AlCrFeNi (w/o Co), and AlCoFeNi (w/o Cr) alloys displayed a brittle trans-granular fracture, as shown in Figure 8a-c, respectively. The fracture in these alloys is of a cleavage type, characterized by facets caused by separation across crystallographic 
planes due to the crack propagation. Fracture of the AlCrFeNi (w/o Co) alloy, shown in Figure 8b, exhibits micro-facets that can be correlated to differences in the morphology of the DR to ID regions, while the first was finer than the latter. The two areas of fractures are marked by rectangles 1 and 2 on Figure 8 b. Coarse microstructure of the AlCoFeNi (w/o Cr) alloy imposed coarser cleavages on the fractographic images (see Figure 8c).
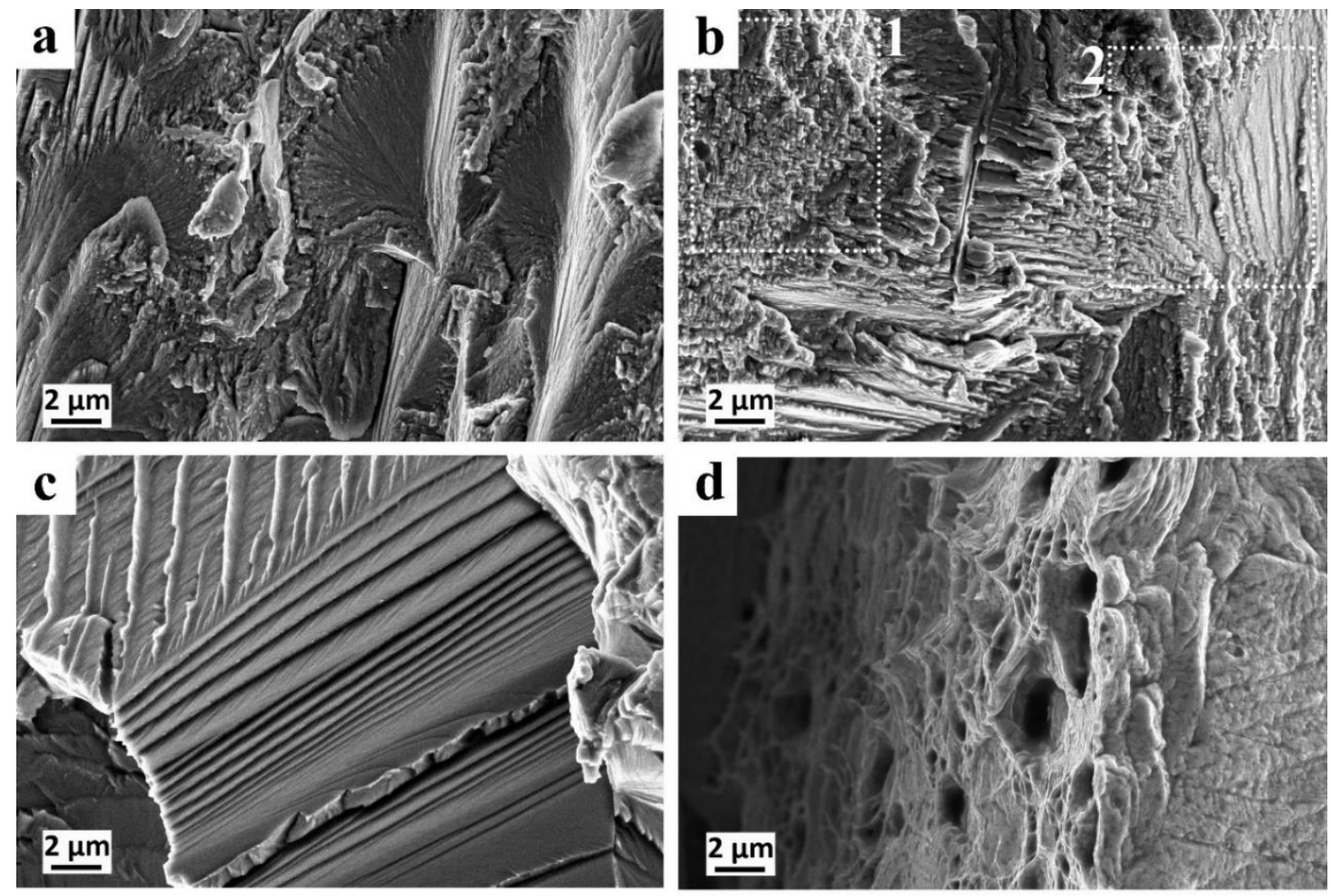

Figure 8. SEM images of the fracture of the (a) $\mathrm{AlCoCrNi}$ (w/o Fe), (b) $\mathrm{AlCrFeNi}(\mathrm{w} / \mathrm{o} \mathrm{Co}$ ), (c) $\mathrm{AlCoFeNi}$ (w/o Cr), and (d) CoCrFeNi (w/o Al) alloys after small punch test (SPT). Rectangles on (b) mark the area of the dendrite (1) and interdendrite (2).

As expected, SPT force vs. displacement curves of the FCC and BCC + B2 dual phase alloys looked completely different, as seen in Figure 9a,b for the AlCrFeNi (w/o Co) alloy (as an example of the $\mathrm{BCC}+\mathrm{B} 2$ mixture alloys studied here) and CoCrFeNi (w/o Al) alloy, respectively. CoCrFeNi (w/o Al, i.e., FCC solid solution) presented a typical ductile material curve. Other studied alloys displayed a "zig-zag" shape curve with pop-ins in the load-displacement curves. Such pop-ins can be the result of discrete events of crack propagation and arrest, which were triggered by an increase of the load $[19,20]$. The weaved B2/BCC microstructure can explain this behavior. The P1 values for the brittle alloys (see Figure 9a, and Table 3) were measured at the first pop-in. The energy values, shown in Table 3, represent the area under the load-displacement curve, until the first pop-in phenomenon (seen at Figure 9a). The P1 values of the AlCoFeNi (w/o Cr) alloy were the largest, and the smallest were measured in the AlCoCrNi (w/o Fe) alloy. These values are in line with their micro-hardness, as shown in Table 2.

Table 3. Mean values of the forces, displacement ( $\delta$ ), and energy, as extracted from the SPT curves of the studied alloys.

\begin{tabular}{cccc}
\hline Alloy & P1 (N) & $\delta(\mathbf{m m})$ & Energy $(\mathbf{J})$ \\
\hline AlCoFeNi (w/o Cr) & $216.0 \pm 63.8$ & $0.05 \pm 0.01$ & $5.6 \pm 3.6$ \\
AlCoCrNi (w/o Fe) & $70.4 \pm 11.4$ & $0.03 \pm 0.01$ & $1.2 \pm 0.4$ \\
AlCrFeNi (w/o Co) & $92.6 \pm 27.3$ & $0.03 \pm 0.08$ & $1.2 \pm 0.7$ \\
\hline
\end{tabular}



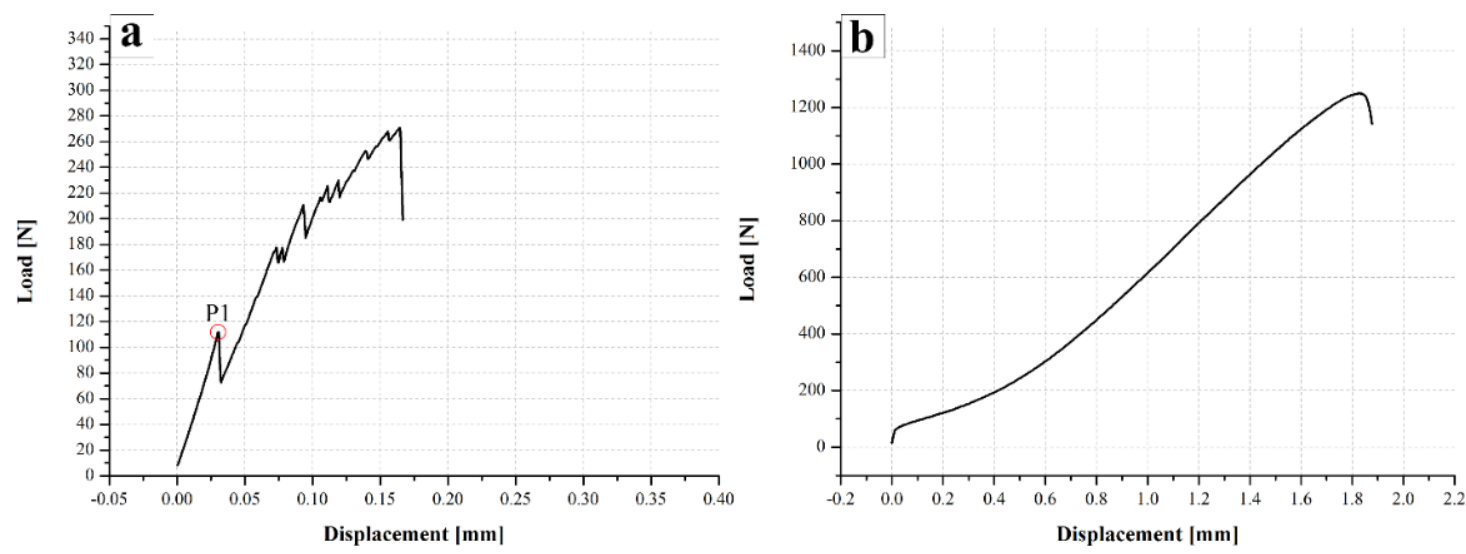

Figure 9. SPT curves of (a) AlCrFeNi (w/o Co) (as an example of the BCC + B2 dual phase alloy) and (b) $\mathrm{CoCrFeNi}$ (w/o Al, Face centered cubic (FCC) solid solution).

\section{Conclusions}

Five quaternary alloys, AlCoCrNi (w/o Fe), AlCoFeNi (w/o Cr), AlCoCrFe (w/o Ni), AlCrFeNi (w/o $\mathrm{Co}$ ), and $\mathrm{CoCrFeNi}(\mathrm{w} / \mathrm{o} \mathrm{Al}$ ), were prepared and characterized to understand the role of each element in the quinary AlFeCrCoNi HEA. CoCrFeNi (w/o Al) was found to be a FCC solid solution. The properties of this alloy were as expected for the FCC-based alloys (i.e., relatively low micro-hardness and ductile fracture post SPT measurement). AlCoFeNi (w/o Cr) was essentially single phase B2. Other alloys exhibited mixed BCC + B2 dual phase content with variable microstructures

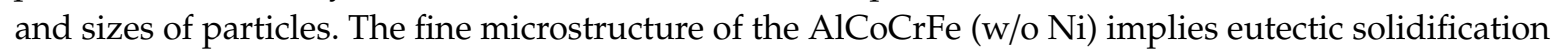
or spinodal decomposition. This fine microstructure imposed remarkable high hardness though was too brittle and unmachinable.

In general, the microstructure of these alloys correlates with the micro-hardness values and follows the Hall-Petch relationship. Studied post SPT fractures of the alloys with the BCC + B2 dual phase content displayed brittle fracture. Among the BCC/B2 mixture alloys, $\mathrm{AlCoCrNi} \mathrm{(w/o} \mathrm{Fe)} \mathrm{and}$ $\mathrm{AlCrFeNi}(\mathrm{w} / \mathrm{o} \mathrm{Co})$ resembled the most quinary $\mathrm{AlCoCrFeNi}$ alloy in terms of microstructure and mechanical properties. The fact that these two alloys exhibited high dislocation density, points to a possible crystallographic mismatch between the BCC and B2 phases in these systems, which was not observed in other studied quaternary and related quinary systems. Moreover, different dislocation density in the B2 and BCC phases point to the different hardness of these phases in the same alloy.

Following these results, it can be proposed that $\mathrm{Al}$ is a $\mathrm{BCC} / \mathrm{B} 2$ stabilizer; $\mathrm{Cr}$ promotes the formation of the $\mathrm{BCC}$ phase (i.e., induces disorder; $\mathrm{Fe}$ and $\mathrm{Co}$ had a similar effect, i.e., minimization of crystallographic mismatch between the BCC and B2 phases).

Author Contributions: G.H. and L.N. contributed equally-prepared the samples and performed the measurements, S.S. - cast the alloys investigated in current research, S.H.- performed and analyzed the SPT, M.P. and L.M.-received a funding, initialized the research, analyzed the data and wrote the manuscript. All authors have read and agreed to the published version of the manuscript.

Funding: Grant ID2-2018 by the Pazi Foundation is greatly acknowledged by Malki Pinkas and Louisa Meshi.

Conflicts of Interest: The authors declare no conflict of interest.

\section{References}

1. Yeh, J.W.; Chen, S.K.; Lin, S.J.; Gan, J.Y.; Chin, T.S.; Shun, T.T.; Tsau, C.H.; Chang, S.Y. Nanostructured high-entropy alloys with multiple principal elements: Novel alloy design concepts and outcomes. Adv. Eng. Mater. 2004, 6, 299-303. [CrossRef]

2. Zhou, Y.J.; Zhang, Y.; Wang, Y.L.; Chen, G.L. Solid solution alloys of AlCoCrFeNiTix with excellent room-temperature mechanical properties. Appl. Phys. Lett. 2007, 90, 181904. [CrossRef] 
3. Dong, Y.; Zhou, K.; Lu, Y.; Gao, X.; Wang, T.; Li, T. Effect of vanadium addition on the microstructure and properties of AlCoCrFeNi high entropy alloy. Mater. Des. 2014, 57, 67-72. [CrossRef]

4. Wang, W.R.; Wang, W.L.; Yeh, J.W. Phases, microstructure and mechanical properties of $\mathrm{Al}_{\mathrm{x}} \mathrm{CoCrFeNi}$ high-entropy alloys at elevated temperatures. J. Alloys Compd. 2014, 589, 143-152. [CrossRef]

5. Linden, Y.; Pinkas, M.; Munitz, A.; Meshi, L. Long-period antiphase domains and short-range order in a B2 matrix of the AlCoCrFeNi high-entropy alloy. Scr. Mater. 2017, 139, 49-52. [CrossRef]

6. Zhang, Y.; Ma, S.G.; Qiao, J.W. Morphology transition from dendrites to equiaxed grains for AlCoCrFeNi high-entropy alloys by copper mold casting and bridgman solidification. Metall. Mater. Trans. A 2012, 43, 2625-2630. [CrossRef]

7. Meshi, L.; Linden, Y.; Munitz, A.; Salhov, S.; Pinkas, M. Retardation of the $\sigma$ phase formation in the AlCoCrFeNi multi-component alloy. Mater. Charact. 2019, 148, 171-177. [CrossRef]

8. Singh, A.K.; Subramaniam, A. On the formation of disordered solid solutions in multi-component alloys. J. Alloys Compd. 2014, 587, 113-119. [CrossRef]

9. Chou, H.P.; Chang, Y.S.; Chen, S.K.; Yeh, J.W. Microstructure, thermophysical and electrical properties in AlxCoCrFeNi $(0 \leq \mathrm{x} \leq 2)$ high-entropy alloys. Mater. Sci. Eng. B Solid-State Mater. Adv. Technol. 2009, 163, 184-189. [CrossRef]

10. Ren, M.; Wang, G.; Li, B. Microstructure and properties of AlCrFeNi intermetallic for electronic packaging shell. In Proceedings of the 2017 18th International Conference on Electronic Packaging Technology (ICEPT), Harbin, China, 16-19 August 2017.

11. Chaudhary, V.; Gwalani, B.; Soni, V.; Ramanujan, R.V.; Banerjee, R. Influence of Cr Substitution and Temperature on Hierarchical Phase Decomposition in the AlCoFeNi High Entropy Alloy. Sci. Rep. 2018, 8, 15578. [CrossRef] [PubMed]

12. Zuo, T.T.; Li, R.B.; Ren, X.J.; Zhang, Y. Effects of Al and Si addition on the structure and properties of CoFeNi equal atomic ratio alloy. J. Magn. Magn. Mater. 2014, 371, 60-68. [CrossRef]

13. Jumaev, E.; Hong, S.H.; Kim, J.T.; Park, H.J.; Kim, Y.S.; Mun, S.C.; Park, J.Y.; Song, G.; Lee, J.K.; Min, B.H. Chemical evolution-induced strengthening on AlCoCrNi dual-phase high-entropy alloy with high specific strength. J. Alloys Compd. 2019, 777, 828-834. [CrossRef]

14. Kao, Y.F.; Chen, T.J.; Chen, S.K.; Yeh, J.W. Microstructure and mechanical property of as-cast, -homogenized, and -deformed $\mathrm{Al}_{\mathrm{x}} \mathrm{CoCrFeNi}(0 \leq \mathrm{x} \leq 2)$ high-entropy alloys. J. Alloys Compd. 2009, 488, 57-64. [CrossRef]

15. Abràmoff, M.D.; Magalhães, P.J.; Ram, S.J. Image processing with imageJ. Biophotonics Int. 2004, 11, 36-42. [CrossRef]

16. Edington, J.W. Practical Electron Microscopy in Materials Science; Van Nostrand Reinhold Company: New York, NY, USA, 1976.

17. Chen, S.; Aitken, Z.H.; Wu, Z.; Yu, Z.; Banerjee, R.; Zhang, Y.W. Hall-Petch and inverse Hall-Petch relations in high-entropy CoNiFeAlxCu1-x alloys. Mater. Sci. Eng. A 2020, 773, 138873. [CrossRef]

18. Munitz, A.; Salhov, S.; Hayun, S.; Frage, N. Heat treatment impacts the micro-structure and mechanical properties of AlCoCrFeNi high entropy alloy. J. Alloys Compd. 2016, 683, 221-230. [CrossRef]

19. Bruchhausen, M.; Altstadt, E.; Austin, T.; Dymacek, P.; Holmström, S.; Jeffs, S.; Lacalle, R.; Lancaster, R.; Matocha, K.; Petzova, J. European standard on small punch testing of metallic materials. Ubiquity Proc. 2018, 1, 11. [CrossRef]

20. Altstadt, E.; Serrano, M.; Houska, M.; García-Junceda, A. Effect of anisotropic microstructure of a 12Cr-ODS steel on the fracture behavior in the small punch test. Mater. Sci. Eng. A 2016, 654, 309-316. [CrossRef]

(C) 2020 by the authors. Licensee MDPI, Basel, Switzerland. This article is an open access article distributed under the terms and conditions of the Creative Commons Attribution (CC BY) license (http://creativecommons.org/licenses/by/4.0/). 